\title{
Supramolecular frameworks based on [60]fullerene hexakisadducts
}

\author{
Andreas Kraft ${ }^{1}$, Johannes Stangl ${ }^{2}$, Ana-Maria Krause ${ }^{1}$, Klaus Müller-Buschbaum ${ }^{2}$ \\ and Florian Beuerle*1,§
}

Open Access

\author{
Full Research Paper \\ Address: \\ ${ }^{1}$ Institut für Organische Chemie \& Center for Nanosystems Chemistry, \\ Universität Würzburg, Am Hubland, 97074 Würzburg, Germany and \\ ${ }^{2}$ Institut für Anorganische Chemie, Universität Würzburg, Am \\ Hubland, 97074 Würzburg, Germany \\ Email: \\ Florian Beuerle* - florian.beuerle@uni-wuerzburg.de \\ * Corresponding author \\ $\S$ Tel.: +49 $93131-83603$ \\ Keywords: \\ fullerenes; hexakisadducts; hydrogen bonding; porous materials; \\ structure elucidation
}

\author{
Beilstein J. Org. Chem. 2017, 13, 1-9. \\ doi:10.3762/bjoc.13.1 \\ Received: 11 August 2016 \\ Accepted: 08 December 2016 \\ Published: 02 January 2017 \\ This article is part of the Thematic Series "Organic porous materials". \\ Guest Editor: S. Bräse \\ (C) 2017 Kraft et al.; licensee Beilstein-Institut. \\ License and terms: see end of document.
}

\begin{abstract}
[60]Fullerene hexakisadducts possessing 12 carboxylic acid side chains form crystalline hydrogen-bonding frameworks in the solid state. Depending on the length of the linker between the reactive sites and the malonate units, the distance of the [60]fullerene nodes and thereby the spacing of the frameworks can be controlled and for the most elongated derivative, continuous channels are obtained within the structure. Stability, structural integrity and porosity of the material were investigated by powder X-ray diffraction, thermogravimetry and sorption measurements.
\end{abstract}

\section{Introduction}

The utilization of confined nanospace in rigid frameworks [1], which are derived from small molecular precursors under dynamic conditions, has emerged as a novel design paradigm for functional materials with the prospect of applications in gas storage [2,3], catalysis [4,5], luminescence [6-9] and sensing [10-13] or optoelectronics [14-16]. Owing to a modular approach, building blocks and cross-linking interactions can be varied over a wide range resulting in metal-organic frameworks (MOFs) [17,18], covalent organic frameworks (COFs) $[19,20]$ or covalent organic cage compounds [21-28] as the most promi- nent examples for such artificial porous materials. Purely organic systems such as COFs usually benefit from very low densities, high thermal stabilities and metal-free synthesis, but in most cases, have the disadvantages of poor crystallinity and limited processability or solution-phase characterization. In contrast, the formation of robust porous structures by means of supramolecular interactions between rigid organic molecules might be a promising alternative thus combining low-weight materials with easy processing. However, the crystallization of stable organic structures possessing permanent porosity is still 
quite challenging and only a limited number of examples for supramolecular crystals based on hydrogen bonding [29-45] or $\pi-\pi$-stacking [46] that retain porosity in the solid state under activation conditions have been reported so far. One possible way to enhance stability and shape-persistency might be the implementation of polyfunctional building blocks in order to strengthen the non-covalent interactions in a cooperative manner. In this regard, [60]fullerene hexakisadducts [47], which can arrange up to twelve functional sites with icosahedral symmetry, exhibit one of the highest degrees of functionalization for organic molecules (see Figure 1). In recent years, a variety of derivatives have been synthesized as spherical branching units [48-53] and, more recently, functionalized fullerene derivatives have been implemented into coordination compounds [54-56]. However, to the best of our knowledge, no fullerene-containing crystalline frameworks retaining permanent porosity in the solvent-free state have been reported so far.

Here, we report on the crystallization of three-dimensional hydrogen-bonding frameworks based on [60]fullerene hexakisadducts bearing twelve carboxylic acid groups icosahedrally arranged on the fullerene surface. By varying the spacer length, the solvent-filled pore systems in the solid-state structures have been tuned and structural features such as porosity of the materials have been investigated by PXRD, TGA analysis and sorption studies.

\section{Results and Discussion}

Recently, we reported on the synthesis and solid-state structure of dodecaacid C2 ( $\mathbf{C n}$ stands for $T_{\mathrm{h}}$ symmetrical hexakis- adducts $\mathrm{C}_{60}\left\{\mathrm{C}\left[\mathrm{COO}\left(\mathrm{CH}_{2}\right)_{n-1} \mathrm{COOH}\right]_{2}\right\}_{6}$, see Figure 1) revealing a complex hydrogen-bonding network in the crystalline state [57]. Based on this initial finding, we also utilized $\mathbf{C 2}$ and elongated derivative $\mathbf{C} 3$ as organic connectivity centers in metal-organic assemblies obtained after reaction with $\mathrm{Zn}^{2+}$ ions [55], however, no crystal structure of metal-free $\mathbf{C 3}$ has been reported yet. As a general packing motif for all fullerenecontaining frameworks, the individual carbon building blocks are arranged in face centered cubic (fcc) packing with the distances between the molecules depending on the spacer length and the mode of cross-linking. For HFF-1 (hydrogen-bonded fullerene framework) derived from $\mathbf{C 2}$, a densely packed structure is observed possessing only very small cavities within the octahedral sites of the fcc packing filled with one $\mathrm{CH}_{2} \mathrm{Cl}_{2}$ molecule (Figure 2a) [57].

In order to obtain porous supramolecular materials, we wondered if elongation of the alkyl spacers may result in increased fullerene-fullerene spacing associated with an enlargement of the cavitities and potential formation of a connected pore system. Therefore, we aimed for the crystallization of $\mathbf{C 3}$ and also synthesized the next homologue $\mathbf{C 4}$ starting from malonate 1 [59] according to a standard two-step protocol via a sixfold Bingel reaction followed by acidic deprotection (Scheme 1). As we observed the insertion of $\mathrm{MeOH}$ molecules into the hydrogen-bonding network of HFF-1 [57], we also tested other polar solvents for crystallization in order to strengthen the supramolecular interactions that hold the networks together. For both $\mathbf{C 3}$ and $\mathbf{C 4}$, we could finally grow single crystals suitable for X-ray diffraction by slow vapor

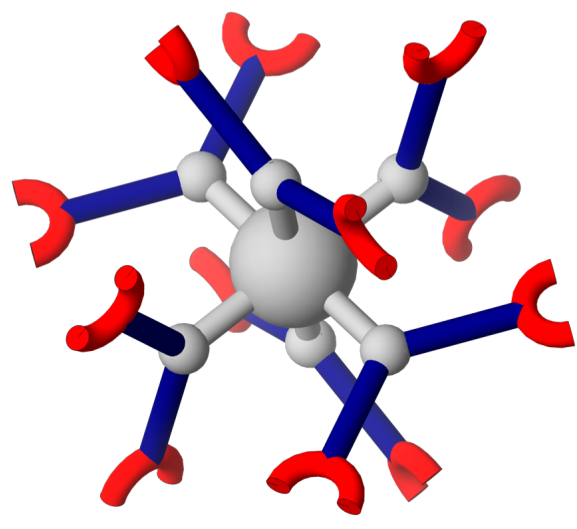

icosahedral symmetry of [60]fullerene hexakisadducts

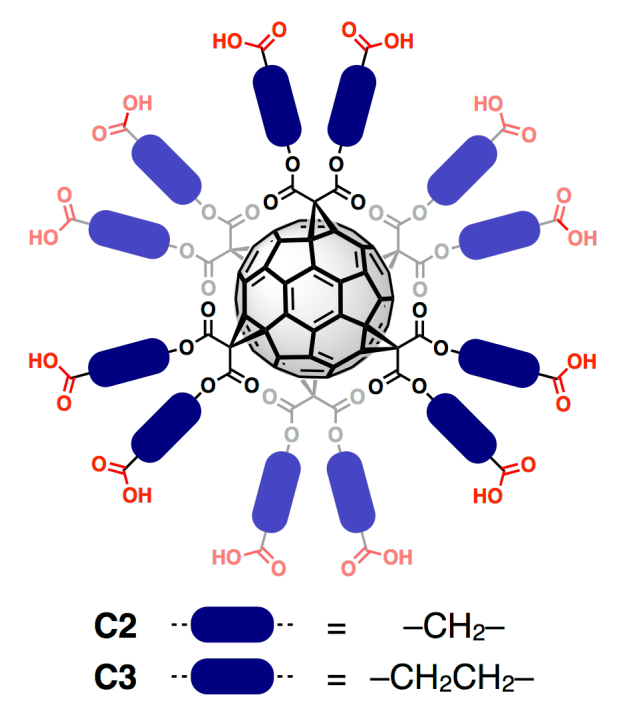

Figure 1: Icosahedral arrangement of functional addends for [60]fullerene hexakisadducts with dodecaacids $\mathbf{C 2}$ and $\mathbf{C 3}$ as prototypical examples for such carbon nanostructures. 
a)

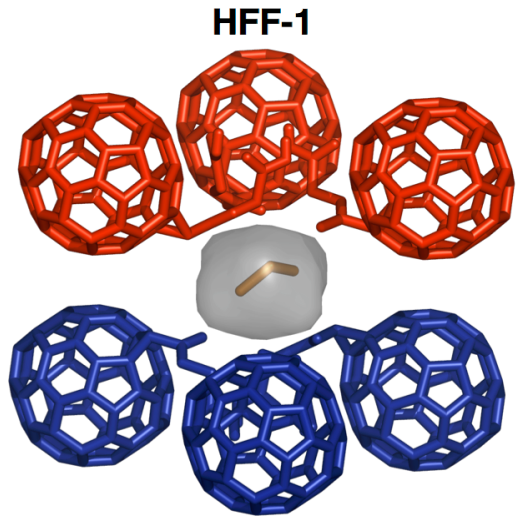

b) HFF-2

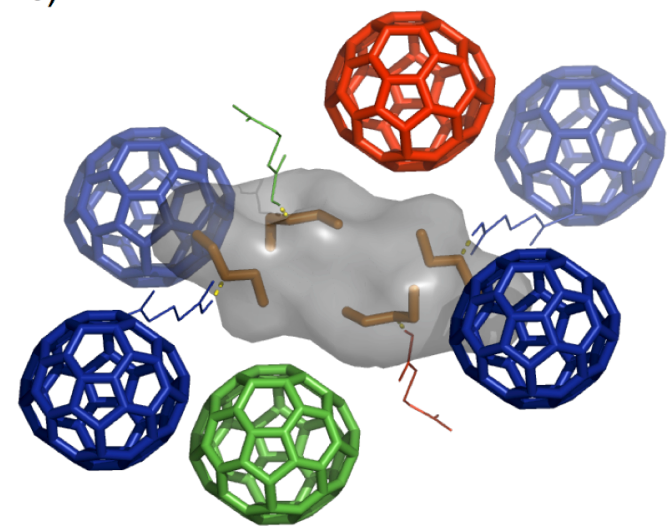

Figure 2: a) Small cavities within the octahedral sites of HFF-1 filled with one $\mathrm{CH}_{2} \mathrm{Cl}_{2}$ molecule [57]; b) isolated cavities containing four Et $\mathrm{O}_{2} \mathrm{O}$ molecules for HFF-2 (void spaces are indicated as grey surfaces and most side arms are omitted for clarity, images are created with PyMOL [58]).

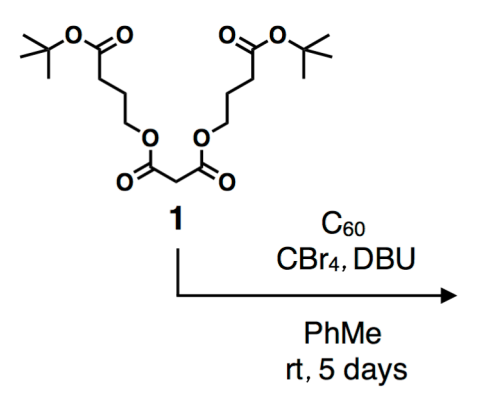

$26 \%$

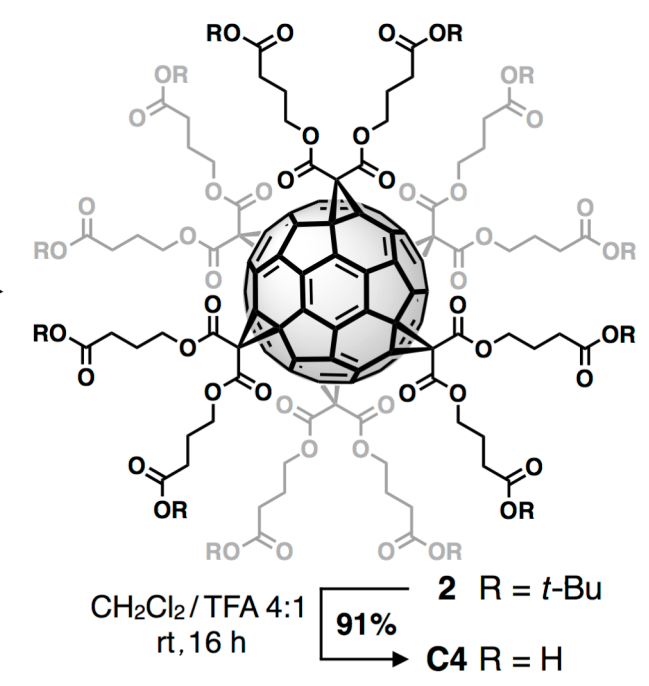

Scheme 1: Synthesis of [60]fullerene dodecaacid C4.

deposition of $\mathrm{Et}_{2} \mathrm{O}$ into $\mathrm{EtOH}$ solutions of both fullerene derivatives thus resulting in the formation of frameworks HFF-2 and HFF-3, respectively.

HFF-2 crystallizes in the triclinic space group $P \overline{1}$ with the composition $\left[\mathbf{C 3}\left(\mathrm{Et}_{2} \mathrm{O}\right)_{4}\right][60]$. Despite the lower symmetry compared to HFF-1, the packing of HFF-2 can still be described as a fcc arrangement of $\mathbf{C 3}$ molecules, which are crosslinked by hydrogen bonding. Thereby, six of the twelve side arms form linear $\mathrm{COOH}$ dimers (four intralayer and two interlayer) and two carboxylic acids are bound to malonate ester groups from adjacent layers (see Figure S10 in Supporting Information File 1). The remaining four carboxylic acid side chains do not participate but rather coordinate one $\mathrm{Et}_{2} \mathrm{O}$ molecule each, resulting in the formation of larger cavities filled with four solvent molecules (Figure 2b). Yet, these voids are still separated from each other and therefore not accessible for solvent exchange and porosity. Then again, dodecaacid C4 possessing elongated butyric acid side chains crystallizes in the trigonal space group $R \overline{3}$ with the composition [C4] $6 \mathrm{Et}_{2} \mathrm{O}$ [61] exhibiting a flattened fcc arrangement of C4 molecules. Figure 3 illustrates the effect of spacer elongation on the fullerene distances, thus leading to larger intralayer spacing and shorter interlayer distances with increasing length of the alkyl spacers separating the hydrogen bonding sites from the malonate units. 
a)

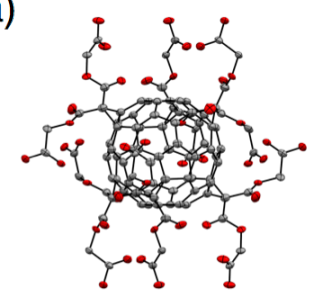

HFF-1

$\left[(\mathbf{C 2})(\mathrm{MeOH})_{6}\right] \cdot \mathrm{CH}_{2} \mathrm{Cl}_{2}$
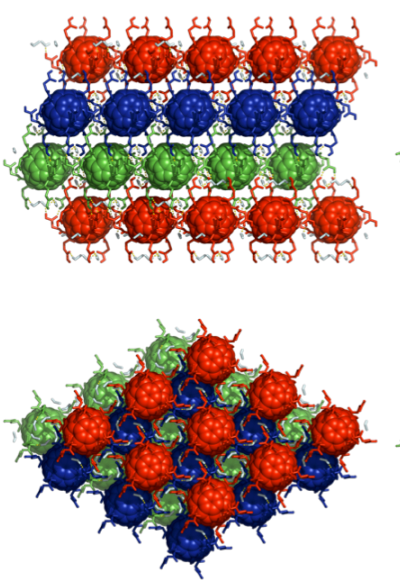

b)

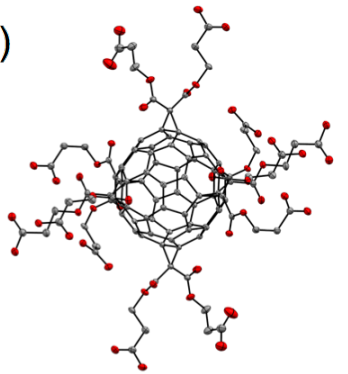

HFF-2

$\left[(\mathbf{C} 3)\left(\mathrm{Et}_{2} \mathrm{O}\right)_{4}\right]$
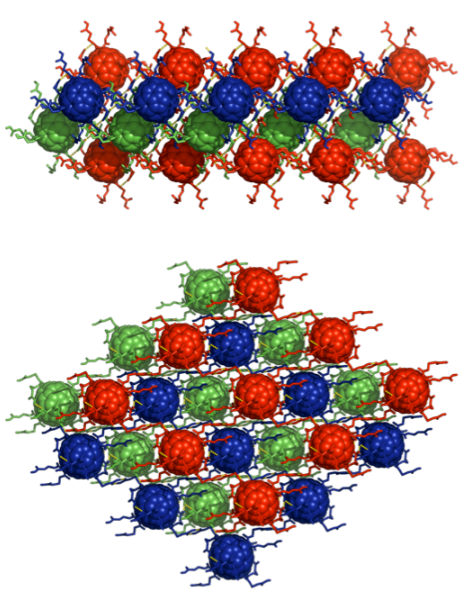

c)

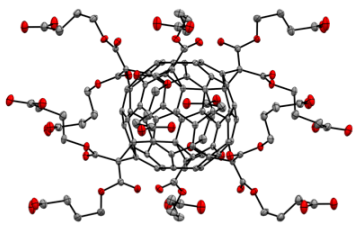

HFF-3

$[(\mathbf{C} 4)] \cdot\left(\mathrm{Et}_{2} \mathrm{O}\right)_{6}$
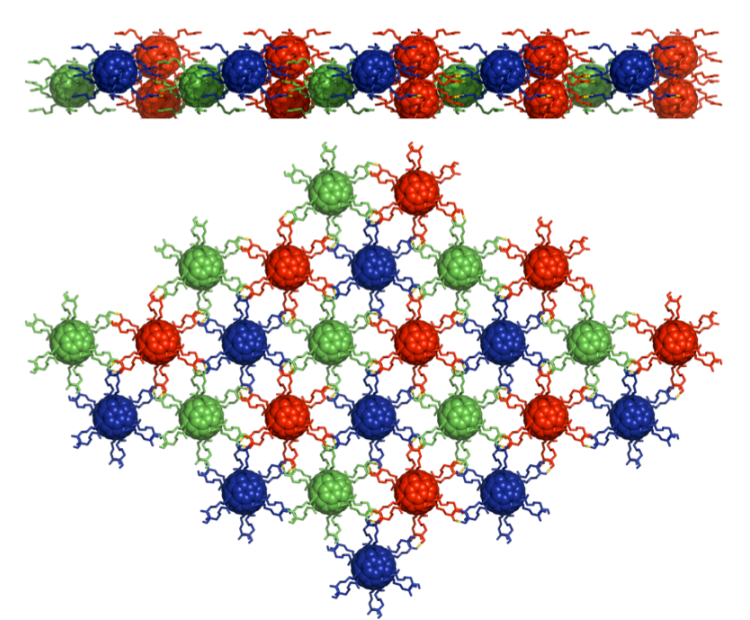

Figure 3: Face centered cubic arrangement of [60]fullerene dodecaacids for frameworks a) HFF-1 [57], b) HFF-2 and c) HFF-3: ORTEP representation of fullerene monomers (top, thermal ellipsoids set to $50 \%$ probability, carbon grey, oxygen red, hydrogen atoms omitted for clarity), side view indicating $\mathrm{ABC}$-type packing (center) and top view indicating enlarged intralayer spacing for elongated derivatives (bottom); images are created with PyMOL [58].

For HFF-3, the butyric acid side arms are stretched out and form six pairs of carboxylic acid dimers with their closest neighbors from the next but one layers (left part of Figure 4). Interestingly, this packing motif results in the interpenetration of two independent hydrogen bonding networks (indicated in purple and cyan in Figure 5). Therefore, the individual layers are densely packed exhibiting linear columns of fullerenes in van-der-Waals distance alternating from the two interpenetrated frameworks (right part of Figure 4 and Figure 5). On the other hand, due to the large intralayer spacing and the linear stretching of the side chains, a continuous pore system is formed along the c axis (right part of Figure 4), which is filled with $\mathrm{Et}_{2} \mathrm{O}$ molecules that are not bound to any carboxlic acids and may therefore be removable upon activation.

In order to elaborate on the materials properties, we synthesized HFF-3 in bulk amounts and studied the thermal stability and sorption properties of this framework. The framework crys- tallizes as anisotropic needles and PXRD measurements in combination with BFDH morphology calculations indicated the structural integrity of the material and the fact that the pore channels are located along the long fiber axis (see Figure S15 in Supporting Information File 1). Thermal treatment of crystalline samples under a microscope indicated partial disintegration and cracking of the crystals at elevated temperatures above $40{ }^{\circ} \mathrm{C}$, presumably due to the removal of solvent molecules. At $198^{\circ} \mathrm{C}$, melting of the crystals occurs (see Figure S12 in the Supporting Information File 1). These findings were also confirmed by TG/DTA measurements for both as-synthesized and preactivated (evacuation at $70{ }^{\circ} \mathrm{C}$ ) samples, thus showing a weight loss of up to $16 \%$ for the nonactivated material after heating to $180{ }^{\circ} \mathrm{C}$ followed by an endothermic signal indicating melting of the crystals (see Figure S17 in Supporting Information File 1). Elemental analysis of an activated sample is in perfect agreement with a solvent-free structure (see Experimental section). 


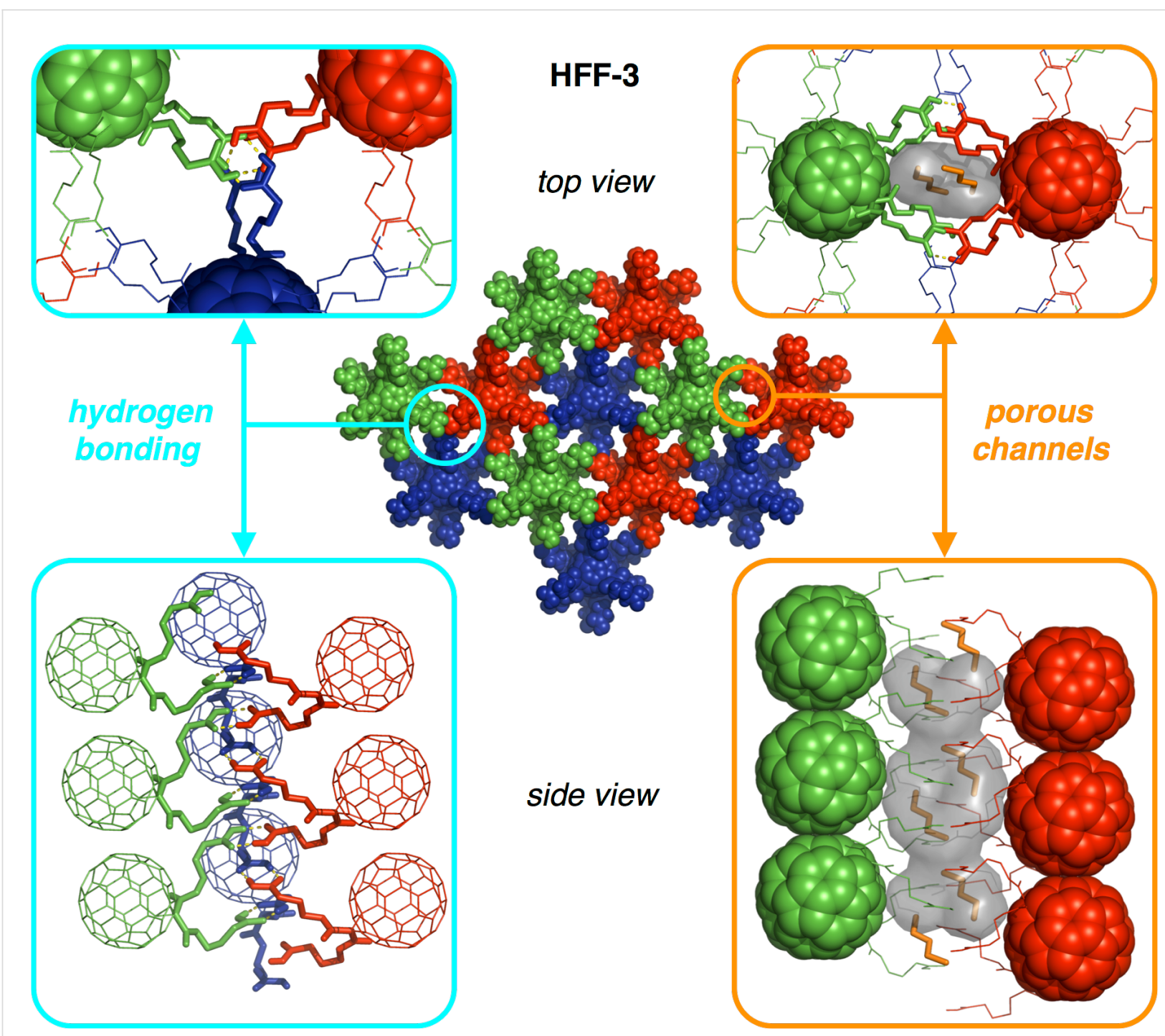

Figure 4: Hydrogen bonding network for HFF-3 (left, hydrogen bonds yellow) and porous channels along the $\mathrm{c}$ axis filled with unbound $\mathrm{Et}_{2} \mathrm{O}$ molecules (right, $\mathrm{Et}_{2} \mathrm{O}$ orange, inner pore surface indicated in grey); images are created with PyMOL [58].

In order to activate HFF-3 and to utilize the channel system for porosity, the compound was activated for 48 hours at different stages of vacuum $\left(10^{-3}\right.$ to $\left.10^{-6} \mathrm{mbar}\right)$ from room temperature to $70{ }^{\circ} \mathrm{C}$. Sorption properties were determined for $\mathrm{N}_{2}$ and Ar gas adsorption via a BET study at $77 \mathrm{~K}$. Therein, the framework shows Henry behavior and no microporosity with a surface area of $40 \mathrm{~m}^{2} \mathrm{~g}^{-1}$ for $\mathrm{N}_{2}$ and only $18 \mathrm{~m}^{2} \mathrm{~g}^{-1}$ for Ar (see Figure S14 in Supporting Information File 1). However, the measured $\mathrm{N}_{2}$ surface area of $40 \mathrm{~m}^{2} \mathrm{~g}^{-1}$ may indicate that the material still retains some porosity since this value is higher than it would be anticipated for sole coverage of the outer surface of the crystals. Since the channels are aligned along the long fiber axis, kinetic effects might also hamper efficient gas uptake. As this result did not point towards accessible microchannels of the crystal structure, the material was checked for structural and chemical integrity subsequent to activation. As stated, elemental analysis fits very well, so that decomposition is unlikely. Therefore, also SEM investigations by electron microscopy were carried out on activated and non-activated samples of HFF-3. They corroborate the strong anisotropic character of crystalline needles of the $\mathrm{X}$-ray structure determination and do not show changes upon activation (see Figure S13 in Supporting in Information File 1). However, powder X-ray diffraction indicates a change in the pattern upon activation (see Figure S16 in Supporting Information File 1). Accordingly, a yet non-identified change in the structure occurs, which may lead to the non-accessibility of the channels. One possible explanation for the observed change upon activation might be that the flexible nature of the alkyl spacers facilitates structural reorganization resulting in a potential blocking of the channels after removal of the solvent mole- 


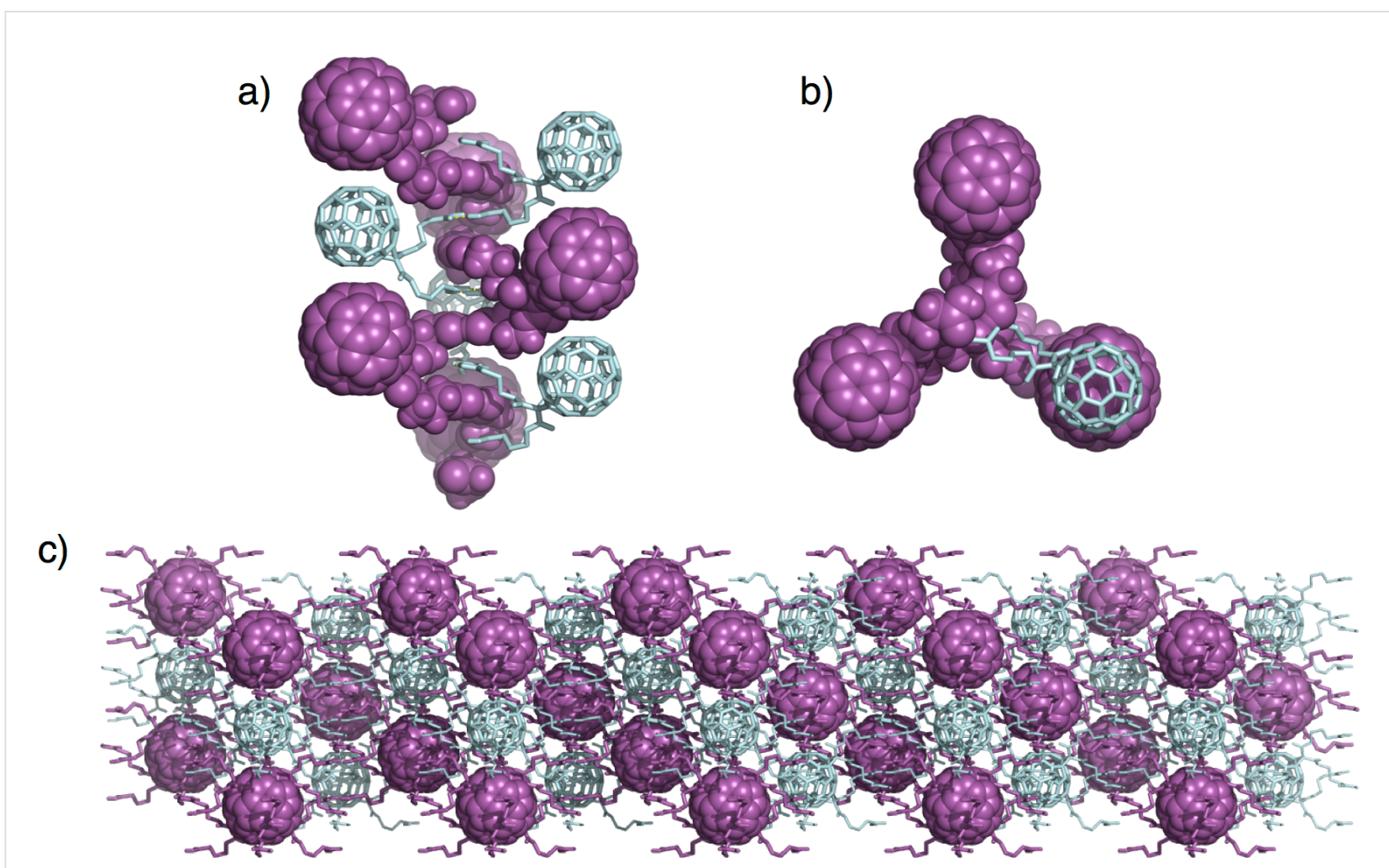

Figure 5: Interpenetration of two distinct hydrogen bonding networks for HFF-3: a) side view indicating the spiral staircase-like cross-linking of individual molecules of $\mathbf{C 4}, \mathrm{b}$ ) top view and c) side view highlighting the interpenetration of two networks colored in purple and cyan.

cules. The $\mathrm{Et}_{2} \mathrm{O}$ molecules appear to play a crucial role for the stabilization of both channel size and shape. For future investigations, the implementation of fullerene derivatives possessing long but rigid spacer units might be beneficial for retaining porosity of such supramolecular crystals.

\section{Conclusion}

We have presented the crystallization of two [60]fullerene dodecaacids possessing three-dimensional hydrogen bonding networks HFF-2 and HFF-3 in the solid state. Different extensions of the linker arms have been investigated for newly synthesized $\mathbf{C 4}$ and compared to the known $\mathbf{C 2}$ and $\mathbf{C 3}$ lengths. Depending on the length of the linker arms, the distance of the fullerene moieties in the framework compounds increases resulting in a new framework structure and giving rise to the idea of permanent porosity for larger fullerene separation. HFF-3 shows channels suitable for microporosity. However, during the activation process not only release of the solvent molecules from the channels but also a structural change occurs that leads to a Henry behavior in BET investigations. In order to rigidify the structures and stabilize the pore systems upon solvent removal, novel fullerene derivatives possessing less flexible spacers need to be designed and synthesized. Efforts in this regard are currently in progress in our laboratories.

\section{Experimental}

Hexakisadduct $\mathbf{C 3}$ [55] and malonate 1 [59] were synthesized according to literature procedures. X-ray crystallography: Bruker D8 Quest diffractometer with Photon 100 CMOS APS detector and Montel multilayer optics monochromated $\mathrm{Cu} K_{\alpha}$ radiation. PXRD diffraction: Bruker D8 Discovery with 1D-Lynxeye detector using $\mathrm{Cu} K_{\alpha}$ radiation (unsplit $K_{\alpha 1}+K_{\alpha 2}$ doublet, mean wavelength $\lambda=154.19 \mathrm{pm}$ ), reflection and transmission geometry.

Hexakisadduct 2: $\mathrm{C}_{60}(565 \mathrm{mg}, 785 \mu \mathrm{mol}, 1$ equiv), malonate 1 (3.10 g, 7.84 mmol, 10 equiv) and $\mathrm{CBr}_{4}(26.0 \mathrm{~g}, 78.4 \mathrm{mmol}$, 100 equiv) were dissolved in dry toluene $(500 \mathrm{~mL})$. DBU (2.34 mL, $15.7 \mathrm{mmol}, 20$ equiv, $60 \mathrm{~mL}$ solution in dry toluene) was added dropwise within 20 minutes resulting in a color change from purple to dark-red. After additional stirring for five days at room temperature, the mixture was passed through a short silica-pad with ethyl acetate as eluent in order to remove the solvent and traces of unreacted $\mathrm{C}_{60}$. After further column chromatographic separation $\left(\mathrm{SiO}_{2}\right.$; toluene/ethyl acetate 10:1), pure hexakisadduct $2(600 \mathrm{mg}, 197 \mu \mathrm{mol}, 25 \%)$ was obtained as a yellow crystalline solid. $\mathrm{mp}>200{ }^{\circ} \mathrm{C} \mathrm{dec} ;{ }^{1} \mathrm{H}$ NMR $\left(400 \mathrm{MHz}^{\mathrm{CDCl}} \mathrm{CDC}_{3}, \mathrm{rt}\right) \delta 1.44\left(\mathrm{~s}, 108 \mathrm{H}, \mathrm{C}\left(\mathrm{CH}_{3}\right)_{3}\right), 1.99\left(\mathrm{~m},{ }^{3} \mathrm{~J}=\right.$ $\left.6.8 \mathrm{~Hz}, 24 \mathrm{H}, \mathrm{CH}_{2} \mathrm{CH}_{2} \mathrm{CH}_{2}\right), 2.31\left(\mathrm{t},{ }^{3} \mathrm{~J}=7.4 \mathrm{~Hz}, 24 \mathrm{H}, \mathrm{CH}_{2} \mathrm{CO}_{2}\right.$ 
$t$-Bu), $4.30 \mathrm{ppm}\left(\mathrm{t},{ }^{3} \mathrm{~J}=6.52 \mathrm{~Hz}, 24 \mathrm{H}, \mathrm{CH}_{2} \mathrm{CH}_{2} \mathrm{CO}_{2} t-\mathrm{Bu}\right) ;{ }^{13} \mathrm{C}$ NMR $\left(100 \mathrm{MHz}, \mathrm{CDCl}_{3}\right.$, rt) $\delta 24.10\left(12 \mathrm{C}, \mathrm{CH}_{2} \mathrm{CH}_{2} \mathrm{CH}_{2}\right), 28.26$ $\left(36 \mathrm{C}, \mathrm{C}\left(\mathrm{CH}_{3}\right)_{3}\right), 31.80\left(12 \mathrm{C}, \mathrm{CH}_{2} \mathrm{CO}_{2} t-\mathrm{Bu}\right), 45.25(6 \mathrm{C}$, $\left.\mathrm{O}_{2} \mathrm{CCH}_{2} \mathrm{CO}_{2}\right), 66.17\left(12 \mathrm{C}, \mathrm{CH}_{2} \mathrm{CH}_{2} \mathrm{CO}_{2} t-\mathrm{Bu}\right), 69.16(12 \mathrm{C}$, $\left.\mathrm{C}_{60} \mathrm{sp}^{3}\right), 80.72\left(12 \mathrm{C}, \mathrm{C}\left(\mathrm{CH}_{3}\right)_{3}\right), 141.15\left(24 \mathrm{C}, \mathrm{C}_{60} \mathrm{sp}^{2}\right), 145.99$ $\left(24 \mathrm{C}, \mathrm{C}_{60} \mathrm{sp}^{2}\right), 163.75\left(12 \mathrm{C}, \mathrm{O}_{2} \mathrm{CCH}_{2} \mathrm{CO}_{2}\right), 171.89 \mathrm{ppm}(12 \mathrm{C}$, $\mathrm{CO}_{2} t$-Bu); UV-vis $\left(\mathrm{CH}_{2} \mathrm{Cl}_{2}\right) \lambda: 281,315$ (sh), 334 (sh) nm; MS (MALDI, DCTB, pos) $\mathrm{m} / z: 3038\left[\mathrm{M}^{+}\right.$; anal, calcd for $\mathrm{C}_{174} \mathrm{H}_{180} \mathrm{O}_{48}$ : C, 68.76; H, 5.97; found: C, 68.87; H, 6.09.

Hexakisadduct C4: TFA $(1.7 \mathrm{~mL})$ was added to a solution of 2 (250 mg, $86.3 \mu \mathrm{mol})$ in $\mathrm{CH}_{2} \mathrm{Cl}_{2}(7 \mathrm{~mL})$. The mixture was stirred for one day at room temperature. The precipitated yellow solid was isolated through decantation. Further purification was carried out by suspending the raw product in $\mathrm{CH}_{2} \mathrm{Cl}_{2}$, centrifugation and collection through decantation. After drying under high vacuum, hexakisadduct C4 (185 mg, $78.2 \mu \mathrm{mol}, 91 \%)$ was obtained as a light-yellow solid. mp $198{ }^{\circ} \mathrm{C}$; ${ }^{1} \mathrm{H}$ NMR (400 MHz, DMSO- $d_{6}$, rt) $\delta 1.85\left(\mathrm{~m}, 24 \mathrm{H}, \mathrm{CH}_{2} \mathrm{CH}_{2} \mathrm{CH}_{2}\right.$ ), 2.27 (t, 24H, $\left.\mathrm{CH}_{2} \mathrm{CO}_{2} \mathrm{H}\right), 4.30$ (t, 24H, $\left.\mathrm{COOCH}_{2}\right), 12.16$ ppm (s br, $\left.12 \mathrm{H}, \mathrm{CO}_{2} H\right) ;{ }^{13} \mathrm{C}$ NMR (100 MHz, DMSO- $\left.d_{6}, \mathrm{rt}\right) \delta 23.47(12 \mathrm{C}$, $\left.\mathrm{CH}_{2} \mathrm{CO}_{2} \mathrm{H}\right), 29.71\left(12 \mathrm{C}, \mathrm{CH}_{2} \mathrm{CH}_{2} \mathrm{CH}_{2}\right), 45.44$ (6C, $\left.\mathrm{O}_{2} \mathrm{CCH}_{2} \mathrm{CO}_{2}\right), 66.35\left(12 \mathrm{C}, \mathrm{COOCH}_{2}\right), 68.67\left(12 \mathrm{C}, \mathrm{C}_{60} \mathrm{sp}^{3}\right)$, $140.71\left(24 \mathrm{C}, \mathrm{C}_{60} \mathrm{sp}^{2}\right), 145.02\left(24 \mathrm{C}, \mathrm{C}_{60} \mathrm{sp}^{2}\right), 162.75(12 \mathrm{C}$, $\left.\mathrm{O}_{2} \mathrm{CCH}_{2} \mathrm{CO}_{2}\right), 173.64$ ppm $\left(12 \mathrm{C}, \mathrm{CO}_{2} \mathrm{H}\right)$; UV-vis $\left(\mathrm{CH}_{2} \mathrm{Cl}_{2}\right) \lambda$ : 281, 315 (sh), 334 (sh) nm; MS (MALDI, DCTB, pos) $\mathrm{m} / \mathrm{z}$ : $2365[\mathrm{M}]^{+}$; anal. calcd for $\mathrm{C}_{126} \mathrm{H}_{84} \mathrm{O}_{48}$ : C, 63.96; $\mathrm{H}, 3.58$; found: C, 63.96; H, 3.58.

Crystal growth of HFF-2: Single crystals suitable for X-ray diffraction have been obtained by slow vapor deposition of $\mathrm{Et}_{2} \mathrm{O}$ into a solution of $\mathbf{C 3}$ in EtOH. CCDC deposition number: 1498265 .

Crystal growth of HFF-3: Single crystals suitable for X-ray diffraction have been obtained by slow vapor deposition of $\mathrm{Et}_{2} \mathrm{O}$ into a solution of $\mathbf{C 4}$ in $\mathrm{EtOH}$. CCDC deposition number: 1498266 .

\section{Supporting Information}

\section{Supporting Information File 1}

Analytical and crystallographic data; SEM, BET, PXRD

and TGA/DTA data.

[http://www.beilstein-journals.org/bjoc/content/

supplementary/1860-5397-13-1-S1.pdf]

\section{Acknowledgements}

The authors would like to thank Dr. David Schmidt for PXRD measurements and Dr. Fabian Schönfeld (Quantachrome) for discussion on the adsorption behavior. Financal support by the Fonds der Chemischen Industrie (Liebig fellowship for FB), the DFG (SPP 1362/2 "Porous MOFs", BE 4808/ 1-2 and MU 1562/5-2) as well as the Bavarian Ministry of Science, Research and the Arts (Collaboratory Research Network "Solar Technologies Go Hybrid") is gratefully acknowledged.

\section{References}

1. Slater, A. G.; Cooper, A. I. Science 2015, 348, 988 doi:10.1126/science.aaa8075

2. Morris, R. E.; Wheatley, P. S. Angew. Chem., Int. Ed. 2008, 47, 4966-4981. doi:10.1002/anie.200703934

3. Mastalerz, M. Chem. - Eur. J. 2012, 18, 10082-10091. doi:10.1002/chem.201201351

4. Corma, A.; García, H.; Llabrés i Xamena, F. X. Chem. Rev. 2010, 110, 4606-4655. doi:10.1021/cr9003924

5. Catti, L.; Zhang, Q.; Tiefenbacher, K. Chem. - Eur. J. 2016, 22, 9060-9066. doi:10.1002/chem.201600726

6. Allendorf, M. D.; Bauer, C. A.; Bhakta, R. K.; Houk, R. J. T. Chem. Soc. Rev. 2009, 38, 1330-1352. doi:10.1039/b802352m

7. Chen, Y.; Ma, S. Rev. Inorg. Chem. 2012, 32, 81-100. doi:10.1515/revic-2012-0003

8. Heine, J.; Müller-Buschbaum, K. Chem. Soc. Rev. 2013, 42, 9232-9242. doi:10.1039/c3cs60232j

9. Meyer, L. V.; Schönfeld, F.; Müller-Buschbaum, K. Chem. Commun. 2014, 50, 8093-8108. doi:10.1039/c4cc00848k

10. Liu, D.; Lu, K.; Poon, C.; Lin, W. Inorg. Chem. 2014, 53, 1916-1924. doi:10.1021/ic402194c

11. Hu, Z.; Deibert, B. J.; Li, J. Chem. Soc. Rev. 2014, 43, 5815-5840. doi:10.1039/c4cs00010b

12. Roy, S.; Chakraborty, A.; Maji, T. K. Coord. Chem. Rev. 2014, 273-274, 139-164. doi:10.1016/j.ccr.2014.03.035

13. Müller-Buschbaum, K.; Beuerle, F.; Feldmann, C. Microporous Mesoporous Mater. 2015, 216, 171-199. doi:10.1016/j.micromeso.2015.03.036

14. Wang, C.; Zhang, T.; Lin, W. Chem. Rev. 2012, 112, 1084-1104. doi:10.1021/cr200252n

15. Rybak, J.-C.; Hailmann, M.; Matthes, P. R.; Zurawski, A.; Nitsch, J.; Steffen, A.; Heck, J. G.; Feldmann, C.; Götzendörfer, S.; Meinhardt, J.; Sextl, G.; Kohlmann, H.; Sedlmaier, S. J.; Schnick, W.; Müller-Buschbaum, K. J. Am. Chem. Soc. 2013, 135, 6896-6902. doi:10.1021/ja3121718

16. Dogru, M.; Bein, T. Chem. Commun. 2014, 50, 5531-5546. doi:10.1039/c3cc46767h

17. Kitagawa, S.; Kitaura, R.; Noro, S. Angew. Chem., Int. Ed. 2004, 43, 2334-2375. doi:10.1002/anie.200300610

18. Férey, G. Chem. Soc. Rev. 2008, 37, 191-214. doi:10.1039/b618320b

19. Feng, X.; Ding, X.; Jiang, D. Chem. Soc. Rev. 2012, 41, 6010-6022. doi:10.1039/c2cs35157a

20. Ding, S.-Y.; Wang, W. Chem. Soc. Rev. 2013, 42, 548-568. doi:10.1039/c2cs35072f

21. Zhang, G.; Mastalerz, M. Chem. Soc. Rev. 2014, 43, 1934-1947. doi:10.1039/c3cs60358j

22. Hasell, T.; Cooper, A. I. Nat. Rev. Mater. 2016, 1, No. 16053. doi:10.1038/natrevmats.2016.53

23. Mastalerz, M.; Schneider, M. W.; Oppel, I. M.; Presly, O Angew. Chem., Int. Ed. 2011, 50, 1046-1051. doi:10.1002/anie.201005301 
24. Schneider, M. W.; Oppel, I. M.; Ott, H.; Lechner, L. G.; Hauswald, H.-J.; Stoll, R.; Mastalerz, M. Chem. - Eur. J. 2012, 18, 836-847. doi:10.1002/chem.201102857

25. Brutschy, M.; Schneider, M. W.; Mastalerz, M.; Waldvogel, S. R. Adv. Mater. 2012, 24, 6049-6052. doi:10.1002/adma.201202786

26. Schneider, M. W.; Oppel, I. M.; Griffin, A.; Mastalerz, M. Angew. Chem., Int. Ed. 2013, 52, 3611-3615. doi:10.1002/anie.201208156

27. Zhang, G.; Presly, O.; White, F.; Oppel, I. M.; Mastalerz, M. Angew. Chem., Int. Ed. 2014, 53, 1516-1520. doi:10.1002/anie.201308924

28. Elbert, S. M.; Rominger, F.; Mastalerz, M. Chem. - Eur. J. 2014, 20 , 16707-16720. doi:10.1002/chem.201404829

29. Lim, S.; Kim, H.; Selvapalam, N.; Kim, K.-J.; Cho, S. J.; Seo, G.; Kim, K. Angew. Chem., Int. Ed. 2008, 47, 3352-3355. doi:10.1002/anie.200800772

30. Comotti, A.; Bracco, S.; Distefano, G.; Sozzani, P. Chem. Commun. 2009, 284-286. doi:10.1039/b820200a

31. Yang, W.; Greenaway, A.; Lin, X.; Matsuda, R.; Blake, A. J.; Wilson, C.; Lewis, W.; Hubberstey, P.; Kitagawa, S.; Champness, N. R.; Schröder, M. J. Am. Chem. Soc. 2010, 132, 14457-14469. doi:10.1021/ja1042935

32. He, Y.; Xiang, S.; Chen, B. J. Am. Chem. Soc. 2011, 133, 14570-14573. doi:10.1021/ja2066016

33. Dalapati, S.; Saha, R.; Jana, S.; Patra, A. K.; Bhaumik, A.; Kumar, S.; Guchhait, N. Angew. Chem., Int. Ed. 2012, 51, 12534-12537. doi:10.1002/anie.201205439

34. Mastalerz, M.; Oppel, I. M. Angew. Chem. 2012, 124, 5345-5348. doi:10.1002/ange.201201174

35. Luo, X.-Z.; Jia, X.-J.; Deng, J.-H.; Zhong, J.-L.; Liu, H.-J.; Wang, K.-J.; Zhong, D.-C. J. Am. Chem. Soc. 2013, 135, 11684-11687. doi:10.1021/ja403002m

36. Natarajan, R.; Bridgland, L.; Sirikulkajorn, A.; Lee, J.-H.; Haddow, M. F.; Magro, G.; Ali, B.; Narayanan, S.; Strickland, P.; Charmant, J. P. H.; Orpen, A. G.; McKeown, N. B.; Bezzu, C. G.; Davis, A. P. J. Am. Chem. Soc. 2013, 135, 16912-16925. doi:10.1021/ja405701u

37. Chen, T.-H.; Popov, I.; Kaveevivitchai, W.; Chuang, Y.-C.; Chen, Y.-S.; Daugulis, O.; Jacobson, A. J.; Miljanić, O. S. Nat. Commun. 2014, 5, No. 5131. doi:10.1038/ncomms6131

38. Li, P.; He, Y.; Arman, H. D.; Krishna, R.; Wang, H.; Weng, L.; Chen, B. Chem. Commun. 2014, 50, 13081-13084. doi:10.1039/c4cc05506c

39. Li, P.; He, Y.; Guang, J.; Weng, L.; Zhao, J. C.-G.; Xiang, S.; Chen, B. J. Am. Chem. Soc. 2014, 136, 547-549. doi:10.1021/ja4129795

40. Lü, J.; Perez-Krap, C.; Suyetin, M.; Alsmail, N. H.; Yan, Y.; Yang, S.; Lewis, W.; Bichoutskaia, E.; Tang, C. C.; Blake, A. J.; Cao, R.; Schröder, M. J. Am. Chem. Soc. 2014, 136, 12828-12831. doi:10.1021/ja506577g

41. Hisaki, I.; Nakagawa, S.; Tohnai, N.; Miyata, M. Angew. Chem., Int. Ed. 2015, 54, 3008-3012. doi:10.1002/anie.201411438

42. Li, P.; He, Y.; Zhao, Y.; Weng, L.; Wang, H.; Krishna, R.; Wu, H.; Zhou, W.; O'Keeffe, M.; Han, Y.; Chen, B. Angew. Chem., Int. Ed. 2015, 54, 574-577. doi:10.1002/anie.201410077

43. Wang, H.; Li, B.; Wu, H.; Hu, T.-L.; Yao, Z.; Zhou, W.; Xiang, S.; Chen, B. J. Am. Chem. Soc. 2015, 137, 9963-9970. doi:10.1021/jacs.5b05644

44. Patil, R. S.; Banerjee, D.; Zhang, C.; Thallapally, P. K.; Atwood, J. L. Angew. Chem., Int. Ed. 2016, 55, 4523-4526. doi:10.1002/anie.201600658
45. Zhou, D.-D.; Xu, Y.-T.; Lin, R.-B.; Mo, Z.-W.; Zhang, W.-X.; Zhang, J.-P. Chem. Commun. 2016, 52, 4991-4994. doi:10.1039/c6cc00366d

46. Kohl, B.; Rominger, F.; Mastalerz, M. Org. Lett. 2014, 16, 704-707. doi:10.1021/ol403383y

47. Yan, W.; Seifermann, S. M.; Pierrat, P.; Bräse, S. Org. Biomol. Chem. 2015, 13, 25-54. doi:10.1039/c4ob01663g

48. Beuerle, F.; Hirsch, A. Chem. - Eur. J. 2009, 15, 7447-7455. doi:10.1002/chem.200900330

49. Nierengarten, J.-F.; lehl, J.; Oerthel, V.; Holler, M.; Illescas, B. M.; Muñoz, A.; Martín, N.; Rojo, J.; Sánchez-Navarro, M.; Cecioni, S.; Vidal, S.; Buffet, K.; Durka, M.; Vincent, S. P. Chem. Commun. 2010, 46, 3860-3862. doi:10.1039/c0cc00034e

50. Dey, S. K.; Beuerle, F.; Olson, M. A.; Stoddart, J. F. Chem. Commun. 2011, 47, 1425-1427. doi:10.1039/c0cc03963b

51. Hörmann, F.; Hirsch, A. Chem. - Eur. J. 2013, 19, 3188-3197. doi:10.1002/chem.201203881

52. Luczkowiak, J.; Muñoz, A.; Sánchez-Navarro, M.; Ribeiro-Viana, R.; Ginieis, A.; Illescas, B. M.; Martín, N.; Delgado, R.; Rojo, J. Biomacromolecules 2013, 14, 431-437. doi:10.1021/bm3016658

53. Muñoz, A.; Sigwalt, D.; Illescas, B. M.; Luczkowiak, J.; Rodríguez-Pérez, L.; Nierengarten, I.; Holler, M.; Remy, J.-S.; Buffet, K.; Vincent, S. P.; Rojo, J.; Delgado, R.; Nierengarten, J.-F.; Martín, N. Nat. Chem. 2016, 8, 50-57. doi:10.1038/nchem.2387

54. Peng, P.; Li, F.-F.; Neti, V. S. P. K.; Metta-Magana, A. J.; Echegoyen, L. Angew. Chem., Int. Ed. 2014, 53, 160-163. doi:10.1002/anie.201306761

55. Kraft, A.; Roth, P.; Schmidt, D.; Stangl, J.; Müller-Buschbaum, K.; Beuerle, F. Chem. - Eur. J. 2016, 22, 5982-5987. doi:10.1002/chem.201505137

56. Kraft, A.; Beuerle, F. Tetrahedron Lett. 2016, 57, 4651-4663. doi:10.1016/j.tetlet.2016.08.082

57. Kraft, A.; Gsänger, M.; Beuerle, F. Eur. J. Org. Chem. 2014, 523-528. doi:10.1002/ejoc.201301298

58. The PyMOL Molecular Graphics System, Version 1.8.2.3; Schrödinger, LLC.

59. Witte, P.; Hörmann, F.; Hirsch, A. Chem. - Eur. J. 2009, 15, 7423-7433. doi:10.1002/chem.200900319

60. Supplementary crystallographic data for HFF-2 can be obtained free of charge from The Cambridge Crystallographic Data Centre via http://www.ccdc.cam.ac.uk/data_request/cif (CCDC 1498265); crystal data: $\mathrm{C}_{114} \mathrm{H}_{60} \mathrm{O}_{48} \cdot 4 \mathrm{C}_{4} \mathrm{H}_{10} \mathrm{O}, M=2494.09 \mathrm{~g} \mathrm{~mol}^{-1}$, triclimic, $P \overline{1}, a=$ 13.1513(5), $b=14.4631(7), c=15.2117(7) \AA, \alpha=107.332(3), \beta=$ 95.752(3) $)^{\circ}, y=94.594(2)^{\circ}, V=2729.6(2) \AA 3, Z=1, \rho_{\text {calc }}=1.517 \mathrm{~g}$ $\mathrm{cm}^{-3}, \mu\left(\mathrm{Cu} K_{\alpha}\right)=1.010 \mathrm{~mm}^{-1}, T=100(2) \mathrm{K} ; 42237$ independent measured reflections. $F 2$ refinement, $R_{1}=0.0490, w R_{2}=0.1302$ (observed), 11068 independent observed reflections $\left(R_{\text {int }}=0.0346\right)$ $\left[\left|F_{0}\right|>4 \sigma\left(\left|F_{0}\right|\right), 2 \Theta \leq 149.4^{\circ}\right], 830$ parameters, no restraints.

61. Supplementary crystallographic data for HFF-3 can be obtained free of charge from The Cambridge Crystallographic Data Centre via http://www.ccdc.cam.ac.uk/data_request/cif (CCDC 1498266); crystal data: $\mathrm{C}_{126} \mathrm{H}_{84} \mathrm{O}_{48} \cdot 6 \mathrm{C}_{4} \mathrm{H}_{10} \mathrm{O}, M=2810.64 \mathrm{~g} \mathrm{~mol}^{-1}$, trigonal, $R \overline{3}, a=$ 33.8114(9), $b=33.8114(9), c=9.8056(3) \AA, \alpha=90, \beta=90, \gamma=120^{\circ}, V$ $=9708.0(6) \AA 3, Z=3, \rho_{\text {calc }}=1.442 \mathrm{~g} \mathrm{~cm}^{-3}, \mu\left(\mathrm{Cu} K_{\mathrm{\alpha}}\right)=0.927 \mathrm{~mm}^{-1}, T$ $=100(2) \mathrm{K} ; 44836$ independent measured reflections. F2 refinement, $R_{1}=0.0488, \mathrm{w} R_{2}=0.1414$ (observed), 4438 independent observed reflections $\left(R_{\text {int }}=0.0442\right)\left[\left|\mathrm{F}_{0}\right|>4 \sigma\left(\left|\mathrm{F}_{0}\right|\right), 2 \Theta \leq 150.28^{\circ}\right], 350$ parameters, no restraints. 


\section{License and Terms}

This is an Open Access article under the terms of the Creative Commons Attribution License

(http://creativecommons.org/licenses/by/4.0), which permits unrestricted use, distribution, and reproduction in any medium, provided the original work is properly cited.

The license is subject to the Beilstein Journal of Organic Chemistry terms and conditions:

(http://www.beilstein-journals.org/bjoc)

The definitive version of this article is the electronic one which can be found at:

doi:10.3762/bjoc.13.1 